\title{
Pre-operative pulmonary assessment and risk factors for post-operative pulmonary complications in elective abdominal surgery in Nigeria
}

\author{
Chinyelu Uchenna Ufoaroh ${ }^{1}$, Prince Udegbunam Ele ${ }^{2}$, Arthur Ebelenna Anyabolu ${ }^{2}$, \\ Emeka Hyacinth Enemuo ${ }^{2}$, Chiemelu Dickson Emegoakor ${ }^{3}$, Chinedu Christian Okoli ${ }^{3}$, \\ Eric Okechukwu Umeh ${ }^{4}$, Ernest Ndukaife Anyabolu ${ }^{5}$
}

1. Chukwuemeka Odumegwu Ojukwu University Teaching Hospital, Medicine.

2. Nnamdi Azikiwe University Teaching Hospital, Nnewi, Medicine.

3. Nnamdi Azikiwe University, Surgery.

4. Nnamdi Azikiwe University Teaching Hospital, Radiology.

5. Chukwuemeka Odumegwu Ojukwu University; Imo State University, Medicine.

\begin{abstract}
Background and Objectives: Post-operative pulmonary complications (PPCs) are recurring causes of rising morbidity and mortality in surgeries. This study sought to evaluate pre-operative risk factors for PPCs in abdominal surgerypatients in Nigeria. Methodology: This was a prospective study in patients booked for surgery in 2014. Biodata, medical his tory, pre-operative respiratory and cardiovascular examination findings, body mass index, serum albumin, serum urea, ventilatory function, chest $\mathrm{x}$-rays and oxygen saturation were obtained. The association between pre-operative variables and PPCs was determined.

Results: The pre-operative spirometry was predominantly restrictive $(62 \%)$. Overall, the prevalence of PPCs was $52 \%$. This included non-productive cough (14\%), isolated productive cough $(10 \%)$, productive cough with abnormal chest finding $(16 \%)$, pneumonia (8\%), pleural effusion (5\%), ARDS (2\%). Percentage predicted FEV1 and FVC were lower in participants with PPCs. $(\mathrm{p}=0.03$ and $\mathrm{p}=0.01$ respectively). Pre-operative cough, shortness of breath and consolidation were associated with PPCs $(\mathrm{p}<$ 0.05). Post-operative respiratory rate and pulse rate in participants with PPCs were higher than the values in those without PPCs $(\mathrm{p}=0.03$ and $\mathrm{p}=0.05)$.

Conclusion: The prevalence of PPCs was high in this study. Pre-operative cough, shortness of breath, consolidation, abnormally low percentage predicted FEV1 and FVC were associated with PPCs.

Keywords: Post-operative pulmonary complications, pre-operative assessment, risk factors, cough, shortness of breath, consolidation, pneumonia, elective abdominal surgeries, Nnewi, Nigeria.

DOI: https://dx.doi.org/10.4314/ahs.v19i1.51

Cite as: Ufoaroh CU, Ele PU, Anyabolu AE, Enemuo EH, Emegoakor CD, Okoli CC, et al. Pre-operative pulmonary assessment and risk factors for post-operative pulmonary complications in elective abdominal surgery in Nigeria. Afri Health Sci. 2019;19(1). 1745-1756. https:// $d x$. doi. org/10.4314/ abs. v19i1.51
\end{abstract}

\section{Introduction}

Pre-operative assessment in all forms of surgery is important, complex, and multi-disciplinary, and is designed

\section{Corresponding author: \\ Ernest Ndukaife Anyabolu, Chukwuemeka Odumegwu \\ Ojukwu University, Medicine; \\ Imo State University, Medicine. \\ Email: enhealer@yahoo.com}

to minimize post-operative complications, morbidity and mortality. ${ }^{1,2}$ The incidence, morbidity and mortality of post-operative pulmonary complications (PPCs) are increasing. ${ }^{3}$ This makes the role of pulmonologists central in pre-operative reviews of patients PCCs is defined as unintended pulmonary abnormalities arising from surgeries that cause identifiable dysfunction with adverse impact on the patients' clinical course leading to high morbidity and mortality. ${ }^{1,4,5,6,17}$

The commonest PPC is pneumonia. Others include atelectasis, bronchitis, bronchospasm, pulmonary embolism, 
respiratory failure, exacerbation of underlying chronic lung disease and respiratory distress syndrome. ${ }^{8-10}$ The prevalence of PPCs varies widely (5-80\%), and is influenced by patients' population and defining criteria. PPCs occur in $25-50 \%$ of major surgeries. ${ }^{11}$

The complications are patient- or procedure-related. Majority develops from changes in lung volumes in response to respiratory muscles dysfunction and chest wall mechanics. Thoracic and upper abdominal surgeries are associated with restrictive lung volume reduction. ${ }^{12,13}$ Reduced vital capacities (50-60\%) may smoother for one week, while functional residual capacity may decrease by about 30\%. Diaphragmatic dysfunction, post-operative pain and splinting of diaphragm may cause atelectasis producing stasis and infection, Bronchospasm may result from the effect of anesthetic agents, tracheal intubation, or aspiration of secretions. ${ }^{14}$

Post-operative pulmonary complications are the most expensive medical outcomes from surgeries. ${ }^{6}$ Studies on pre-operative assessment have been conducted in the Americas. ${ }^{7,15}$ This study therefore sought to evaluate pre-operative and other factors which might influence PPCs in patients undergoing abdominal surgery in Nigeria, with a view to reducing adverse outcomes,

\section{Materials and methods}

This was a prospective study on patients booked for elective abdominal surgery between February, 2014 and April, 2015, in Nnamdi Azikiwe University Teaching Hospital (NAUTH), Nnewi, SouthEast Nigeria. The study subjects consisted of 50 patients $>18$ years, consecutively recruited from those booked for major elective abdominal surgeries during this period. Those with impaired consciousness were excluded. About 120 abdominal surgeries, $60 \%$ emergencies and 40\% elective, were performed annually.

\section{Sample size calculation}

The minimum sample size was determined by Fishers' formula. ${ }^{16}$

Where:

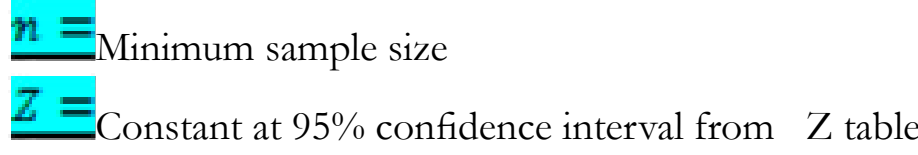

$\underline{P}=$ Average prevalence of PPCs following non-cardiothoracic surgeries ${ }^{17}(10.5 \%)$.

Using and taking Precision at 95\% confidence interval $=0.05$

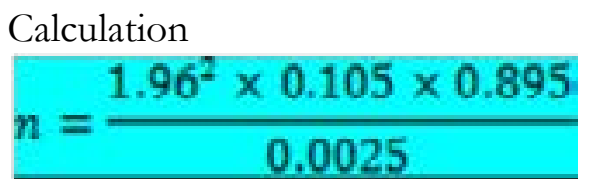

\section{$n=144.4$}

Applying the formula for calculation of sample size with population less than ten thousand.

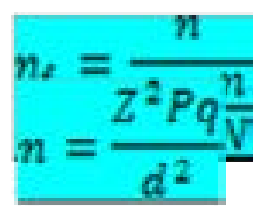

$n_{f} \rightarrow$ The derived sample size when population is less than 10,000

$\underline{n} \rightarrow$ The desired sample size when the population is more than 10,000

$N \rightarrow$ The estimate of the population

All consenting patients booked for elective abdominal surgery between February 2014 and April 2015 were assessed. A total of 50 participants were enrolled into the study to cover for possible attrition and also to increase the power of the study.

The hospital Ethics Committee approved this study. Informed written consent was obtained from each participant.

Computerized portable micro lab spirometer $3500 \mathrm{UK}$ V.6.00, was used to perform ventilatory function tests.

\section{Data collection}

The following data were obtained by the researchers for each subject, using a questionnaire.

Demographic data; age, sex

Respiratory symptoms: cough, shortness of breath, wh eeze 
Co-morbidities: hypertension, diabetes, asthma, HIV status, indication for surgery.

Social history: smoking and pack years of smoking. Clinical examination: standing height $(\mathrm{m})$, weight $(\mathrm{kg})$, pulse rate (beats/min), blood pressure $(\mathrm{mmHg})$, respiratory rate (cycles/min), crackles. The participants pre-operatively were grouped into the American Society of Anesthesiologist (ASA) classes.

Relevant investigations: chest radiograph, lung function tests, oxygen saturation, serum urea and albumin.

Spirometry: This was performed with the subjects relaxed, sitting, and without nose clips, tight clothing or removable dentures in the mouth. The purpose of the tests was explained to them. Each performed forced expiratory manoeuvers, from total lung capacity to residual volume, to obtain measurements for peak expiratory force (PEF), forced vital capacity (FVC) and forced expiratory volume in one second (FEV1). The best PEF, FVC and FEV1 from technically satisfactory forced expiratory manoeuvers were selected as representative values. Five minutes were allowed between manoeuvers to enable the participant rest. ${ }^{18}$

\section{Relevant intra-operative parameters}

Data on the procedure-related risk factors for PPCs such as duration of surgery, anesthetic agents, analgesics, type of incision, were retrieved from the operation notes of each participant.

\section{Post-operative parameters}

Each participant has a respiratory and cardiovascular sys- tems examination, and oxygen saturation performed 48 hours post-operatively.

\section{Data analysis}

The data were analyzed using SPSS version 21.0. The association between categorical variables were compared using Pearson Chi square test and/or Fishers Exact test. The mean difference of the continuous variables was compared using Students t tests. Univariate linear regression analysis was used to determine the strength of the pre-operative variables to predict the PPCs. All tests were two-tailed. $\mathrm{P} \leq 0.05$ was taken as statistically significant.

\section{Definition of Terms}

PPC is defined as unintended pulmonary abnormalities that occur as a result of surgery which cause identifiable dysfunction. $^{3}$

Cough is defined as a common reflex action that clears the throat of mucus or foreign irritants.

\section{Results}

Fifty participants were studied. Their mean age was $50.60 \pm 13.70$ years, range $26-72$ years and age groups evenly distributed. Females constituted $62.0 \%$ and males $38.0 \%$.

Intra-abdominal malignancy $(52.0 \%)$ was the major indication for surgery. Others were ventral hernia $(16.0 \%)$, uterine fibroid $(10.0 \%)$, benign prostatic hypertrophy $(8.0 \%)$, renal stone $(8.0 \%)$, cholecystitis $(4.0 \%)$ and liver abscess $(2.0 \%)$.

Majority $(98 \%)$ of the patients were within ASA class I-III; $12 \%$ had crepitations, whereas $6 \%$ had chronic obstructive airway diseases. Pre-operative respiratory symptoms were observed in $44 \%$ of the patients. Cough was the most common symptom (Table 1). 


\begin{tabular}{|l|l|}
\hline \multicolumn{2}{|l|}{ Table 1: Pre-operative risks in study subjects } \\
\hline Risk factors & Frequency (\%) \\
\hline Obesity & $\mathbf{1 4 ( 2 8 )}$ \\
\hline Smoking & $\mathbf{6 ( 1 2 )}$ \\
\hline Hypertension & $\mathbf{1 3}(\mathbf{2 6})$ \\
\hline Diabetes mellitus & $\mathbf{5 ( 1 0 )}$ \\
\hline Human Immunodeficiency Virus infection & $\mathbf{2 ( 4 )}$ \\
\hline American Society of Anesthesiology class & \\
\hline I & $\mathbf{1 1 ( 2 2 )}$ \\
\hline II & $\mathbf{1 8 ( 3 6 )}$ \\
\hline III & $\mathbf{2 0}(\mathbf{4 0})$ \\
\hline IV & $\mathbf{1 ( 2 )}$ \\
\hline Chronic obstructive airway diseases & $\mathbf{3 ( 6 )}$ \\
\hline Pre-operative crepitation & $\mathbf{5 ( 1 0 )}$ \\
\hline Pre-operative respiratory symptoms & \\
\hline Snoring & $\mathbf{9 ( 3 1 . 0 )}$ \\
\hline Shortness of breath & $\mathbf{6 ( 2 0 . 7 )}$ \\
\hline Cough & $\mathbf{1 3 ( 4 4 . 8 )}$ \\
\hline Wheezing & $\mathbf{1 ( 3 . 4 )}$ \\
\hline Hypoalbuminaemia (<30g/dl) & $\mathbf{7 ( 1 4 )}$ \\
\hline Urea( $>10$ mmol/l) & $\mathbf{7 ( 1 4 )}$ \\
\hline & \\
\hline
\end{tabular}

The patients presented with reduced FVC, FEV1 and PEF. These were dominantly restrictive $(62 \%)$, observed with increasing age (Tables 2).

Thirty-nine (78\%) subjects had abnormal pre-operative chest radiograph, some showed multiple abnormalities. The abnormalities observed were aortic unfolding
$(28.7 \%)$ in subjects, topping the list, followed by pneumonic consolidation $(20.3 \%)$, cardiomegaly $(17.8 \%)$, elevated diaphragm $(7.9 \%)$, lung volume loss $(7.9 \%)$, features of fibrosis $(5.0 \%)$, pleural effusion $(5.0 \%)$, tracheal deviation $(3.0 \%)$ and the least, cavity $(0.9 \%)$ and hyperinflation $(0.9 \%)$. 
Table 2: Baseline lung function of the participants

\begin{tabular}{|l|l|l|l|l|l|}
\hline Age & Sex & $\begin{array}{l}\mathbf{F E V}_{\mathbf{1}}(\mathbf{L}) \\
\text { Median }\end{array}$ & $\begin{array}{l}\text { FVC(L) } \\
\text { Median }\end{array}$ & $\begin{array}{l}\mathbf{F E V}_{\mathbf{1}} / \mathbf{F V C} \\
\mathbf{F} / \mathbf{M})\end{array}$ & $\begin{array}{l}\text { PEF(L) } \\
\text { Median }\end{array}$ \\
\hline $26-30$ & F/M & $2.28 /-$ & $2.28 /-$ & $94 /-$ & $3.54 /-$ \\
\hline $31-35$ & F/M & $2.22 / 2.71$ & $2.26 / 3.23$ & $91 / 84$ & $3.25 / 3.93$ \\
\hline $36-40$ & F/M & $1.02 /-$ & $1.06 /-$ & $96 /-$ & $1.34 /-$ \\
\hline $41-45$ & F/M & $1.54 / 0.21$ & $1.54 / 3.58$ & $99 / 93$ & $2.87 / 6.19$ \\
\hline $46-50$ & F/M & $1.125 / 2.93$ & $1.14 / 3.15$ & $98 / 93$ & $3.19 / 3.28$ \\
\hline $51-55$ & F/M & $1.50 / 2.21$ & $1.51 / 2.39$ & $92 / 88$ & $2.17 / 4.40$ \\
\hline $56-60$ & F/M & $1.38 / 1.94$ & $1.42 / 2.17$ & $96 / 91$ & $2.13 / 3.22$ \\
\hline $61-65$ & F/M & $1.50 / 0.42$ & $1.69 / 2.79$ & $96 / 90$ & $2.87 / 3.75$ \\
\hline$>65$ & F/M & $1.43 / 1.65$ & $1.61 / 1.75$ & $91 / 95$ & $2.25 / 2.48$ \\
\hline $\begin{array}{l}\text { FEV1=forced expiratory volume in 1 second. FVC=forced vital capacity. F=female. M=male. PEF= peak } \\
\text { expiratory flow }\end{array}$ \\
\hline
\end{tabular}

The incision types were dominantly upper abdominal (supra-umbilical) midline $(66.0 \%)$, trailed by lower abdominal (infra-umbilical) midline $(26.0 \%)$ and flank (8.0\%). Muscle relaxants used were short-acting $(60.0 \%)$, long acting $(26.0 \%)$, none $(14.0 \%)$. Majority $(56 \%)$ of the surgery lasted $<2$ hours. The type of anesthesia employed were principally general using endotracheal tube (56\%), general without using endotracheal tube $(30 \%)$ and local $14 \%$.

Post-operative pulmonary complications were observed in $52 \%$ of the subjects. These comprised of new onset productive cough plus crepitation without radiographic features of pneumonia (16\%), isolated non-productive cough $(14 \%)$, isolated productive cough $(10 \%)$, pneumonia $(7 \%)$, pleural effusion $(2 \%)$ and hypoxemia, widespread coarse crepitations and pulmonary chest infiltrates (suggesting acute respiratory distress syndrome (ARDS) $(2 \%)$.

No significant association was observed between PPCs and the indications for surgery, namely, benign prostatic hypertrophy $(p=0.09)$, cholecystitis $(p=0.49)$, fibroid $(p=0.35)$, intra-abdominal malignancy $(p=0.79)$, liver abscess $(p=0.48)$, renal stone $(p=0.34)$, ventral hernia $(\mathrm{p}=0.70)$. Although intra-abdominal malignancy made up $52 \%$ of the indications for surgery, no significant association was found between intra-abdominal malignancy and PPCs.

There was significant association between PPCs and presence of cough $(p=0.01)$, as well as shortness of breath $(\mathrm{p}<0.01)$. Other variables have no such association (Table 3). 
Table 3: Risk factors Versus Post-operative pulmonary complications

\begin{tabular}{|c|c|c|c|c|}
\hline Risk factors & $\begin{array}{l}\text { Absence of } \\
\text { POPC }\end{array}$ & $\begin{array}{l}\text { Presence of } \\
\text { POPC }\end{array}$ & $\mathrm{X}^{2}$ & p-value \\
\hline \multicolumn{5}{|l|}{$\begin{array}{l}\text { Age of patient } \\
<50 \\
>50\end{array}$} \\
\hline$<60$ years & 17 & 16 & 0.48 & 0.37 \\
\hline$>60$ years & 7 & 10 & & \\
\hline \multicolumn{5}{|l|}{ Obesity } \\
\hline $\mathrm{BMI}<30 \mathrm{~kg} / \mathrm{m}^{2}$ & 17 & 19 & 0.03 & 0.90 \\
\hline $\mathrm{BMI} \geq 30 \mathrm{~kg} / \mathrm{m}^{2}$ & 7 & 7 & & \\
\hline \multicolumn{5}{|l|}{ ASA class } \\
\hline I-II & 15 & 14 & 1.76 & 0.40 \\
\hline III & 8 & 12 & & \\
\hline IV & 1 & - & & \\
\hline \multicolumn{5}{|c|}{ Pre-operative respiratory symptoms } \\
\hline Snoring & 5 & 4 & 0.251 & 0.446 \\
\hline Shortness of breath & - & 6 & 6.29 & $0.014 *$ \\
\hline Cough & 1 & 12 & 11.35 & $0.001 *$ \\
\hline Wheezing & - & 1 & 0.942 & 0.520 \\
\hline \multicolumn{5}{|l|}{ Muscle relaxants } \\
\hline Short acting & 13 & 17 & 3.12 & 0.22 \\
\hline Long acting & 4 & 9 & 2.09 & 0.15 \\
\hline None & 5 & 2 & 1.70 & 0.18 \\
\hline $\begin{array}{l}\text { COPD } \\
\text { No } \\
\text { Yes }\end{array}$ & 1 & 2 & 0.28 & 1.00 \\
\hline Co-morbidity & 15 & 17 & 4.92 & 0.57 \\
\hline \multicolumn{5}{|l|}{ Duration of surgery } \\
\hline$>2$ hours & 11 & 11 & 0.06 & 0.80 \\
\hline$<2$ hours & 13 & 15 & & \\
\hline
\end{tabular}

The percentage predicted FEV1 and percentage predict- $(\mathrm{p}=0.01)$ (Table 4). Pre-operative consolidation, unlike ed FVC of the subjects that developed PPCs were signifi- other chest radiograph findings, has significant associacantly low compared to those without the complications tion with PPCs (Table 5). 


\begin{tabular}{|c|c|c|c|}
\hline PR RISK FACTORS & $\begin{array}{l}\text { mean } \pm \text { standard } \\
\text { deviation }\end{array}$ & $\mathrm{T}$ & P-value \\
\hline \multicolumn{4}{|l|}{ AGE } \\
\hline Absence of POPC & $50.9 \pm 13.0$ & 0.03 & 0.87 \\
\hline Presence of POPC & $50.3 \pm 14.6$ & & \\
\hline \multicolumn{4}{|l|}{ BMI } \\
\hline Absence of POPC & $26.14 \pm 6.0$ & 0.34 & 0.57 \\
\hline Presence of POPC & $27.3 \pm 7.5$ & & \\
\hline \multicolumn{4}{|l|}{ FEV1 } \\
\hline Absence of POPC & $1.96 \pm 0.72$ & 0.11 & 0.75 \\
\hline Presence of POPC & $1.89 \pm 0.82$ & & \\
\hline \multicolumn{4}{|l|}{ Predicted FEV1(\%) } \\
\hline Absence of POPC & $81.38 \pm 19.01$ & 5.14 & \\
\hline Presence of POPC & $67.31 \pm 24.30$ & & \\
\hline \multicolumn{4}{|c|}{ Predicted FVC(\%) FVC(\%) } \\
\hline Absence of POPC & $76.54 \pm 19.65$ & 6.60 & 0.01 \\
\hline Presence of POPC & $61.23 \pm 22.23$ & & \\
\hline \multicolumn{4}{|l|}{ PEF } \\
\hline Absence of POPC & $3.26 \pm 1.40$ & 0.11 & 0.74 \\
\hline Presence of POPC & $3.40 \pm 1.57$ & & \\
\hline \multicolumn{4}{|l|}{ FEV1/FVC ratio } \\
\hline Absence of POPC & $92.05 \pm 9.47$ & 0.20 & \\
\hline Presence of POPC & $91.01 \pm 7.06$ & & \\
\hline \multicolumn{4}{|l|}{ Urea } \\
\hline Absence of POPC & $5.2 \pm 3.4$ & 0.38 & 0.54 \\
\hline Presence of POPC & $5.2 \pm 4.9$ & & \\
\hline \multicolumn{4}{|l|}{ Albumin } \\
\hline Absence of POPC & $37.1 \pm 8.0$ & 0.03 & 0.96 \\
\hline Presence of POPC & $37.2 \pm 6.2$ & & \\
\hline
\end{tabular}

\section{Table 5: Pre-operative plain chest radiograph findings and post- operative pulmonary complication}

\begin{tabular}{|l|l|l|l|l|}
\hline Feature & $\begin{array}{l}\text { Absence } \\
\text { of POPC }\end{array}$ & $\begin{array}{l}\text { Presence of } \\
\text { POPC }\end{array}$ & $X^{2}$ & P-value \\
\hline Cavity & - & 1 & 0.80 & 0.52 \\
\hline Features of fibrosis & 1 & 4 & 1.745 & 0.351 \\
\hline Pneumonic consolidation & 5 & 16 & 8.489 & 0.005 \\
\hline Pleural effusion & 2 & 3 & $1 . .30$ & 1.00 \\
\hline Tracheal deviation & 1 & 2 & 0.15 & 0.70 \\
\hline Elevated hemidiaphragm & 3 & 5 & 1.40 & 0.70 \\
\hline Hilar opacity & - & 2 & 1.64 & 0.50 \\
\hline Lung volume loss & 2 & 6 & 3.84 & 0.06 \\
\hline Aortic unfolding & 14 & 15 & 0.002 & 1.00 \\
\hline Hyperinflation & 1 & - & 1.30 & 0.48 \\
\hline Cardiomegaly & 9 & 9 & 0.02 & 1.00 \\
\hline POPC=Post-operative pulmonary complications. X $X^{2}$ chi square. &
\end{tabular}


The mean respiratory rate and mean pulse rate were significantly higher in those with PPCs than in those without complications ( $p=0.03$ and $p=0.05$ respectively) (Table 6$)$. Pre-operative cough predicted PPCs in the study, (OR
0.045, $\mathrm{p}=0.02,95 \%$ confidence interval 0.003-0.634), whereas pneumonic consolidation $(\mathrm{p}=0.12)$, predicted FEV1 $(p=0.57)$, and predicted FVC $(p=0.69)$ did not (Table 7 and 8).

\begin{tabular}{|c|c|c|c|c|}
\hline \multicolumn{5}{|c|}{$\begin{array}{l}\text { Table 6: Examination findings and post-operative pulmonary } \\
\text { complication }\end{array}$} \\
\hline & $\begin{array}{l}\text { Presence of } \\
\text { POPC } \\
(\text { mean } \pm \text { SD) }\end{array}$ & $\begin{array}{l}\text { Absence of } \\
\text { POPC } \\
(\text { mean } \pm \text { SD) }\end{array}$ & $T$ & P-value \\
\hline Respiratory rate Pre-op & $22.0 \pm 4.30$ & $20.7 \pm 2.30$ & 1.68 & 0.20 \\
\hline Post-op & $29.9 \pm 8.10$ & $25.3 \pm 6.10$ & 5.23 & 0.03 \\
\hline \multirow[t]{2}{*}{ Pulse rate } & $83.4 \pm 12.6$ & $83.5 \pm 12.60$ & 0.01 & 0.97 \\
\hline & $100.4 \pm 20.50$ & $88.8 \pm 20.70$ & 3.98 & 0.05 \\
\hline \multirow[t]{2}{*}{$\mathrm{O}_{2}$ saturation } & $95.0 \pm 8.20$ & $97.0 \pm 1.60$ & 1.43 & 0.24 \\
\hline & $93.2 \pm 5.00$ & $94.9 \pm 5.00$ & 1.95 & 0.17 \\
\hline
\end{tabular}

\begin{tabular}{|l|l|}
\hline Table 7: Post-operative pulmonary complication & Frequency N(percent) \\
\hline Complications & $7(14 \%)$ \\
\hline Non-productive cough only & $5(10 \%)$ \\
\hline Productive cough only & $8(16 \%)$ \\
\hline Productive cough + crepitation (nil CXR features of pneumonia) & $4(8 \%)$ \\
\hline Pneumonia & $1(2 \%)$ \\
\hline Pleural effusion & $1(2 \%)$ \\
\hline $\begin{array}{l}\text { Hypoxaemia+ wide spread coarse crepitations + pulmonary chest } \\
\text { infiltrate ( ?ARDS) }\end{array}$ & $24(48 \%)$ \\
\hline No POPC & \multicolumn{2}{|l|}{} \\
\hline $\begin{array}{l}\text { POPC=Post-operative pulmonary complications. CXR: chest radiograph. ? ARDS= suspected } \\
\text { Acute Respiratory Distress syndrome }\end{array}$ \\
\hline
\end{tabular}

\begin{tabular}{|l|l|l|l|l|}
\hline Table 8: Logistic regression table for the significant variables \\
\hline Significant variables & P value & Odd ratio & Lower CI & $\begin{array}{l}\text { Upper } \\
\text { CI }\end{array}$ \\
\hline Pneumonic consolidation & 0.115 & 0.29 & 0.062 & 1.354 \\
\hline Pre-operative cough & $0.021^{*}$ & 0.045 & 0.003 & 0.634 \\
\hline Predicted FEV1 & 0.571 & 0.975 & 0.893 & 1.065 \\
\hline Predicted FVC & & & & \\
\hline$* P \leq 0.05$ =significant, CI; confidence interval, & 0.688 & 0.981 & 0.895 & 1.076 \\
\hline
\end{tabular}




\section{Discussion}

This study showed that pre-operative cough, shortness of breath, pneumonic consolidation, low percentage predicted FEV1 and low percentage predicted FVC were common in PPCs in patients undergoing elective abdominal surgery.

In this study, no significant association was observed between age and PPCs, similar to that by Kanat.et $\mathrm{al}^{20}$ whose sample size was 60 , but differing from the studies by Brooks-Brunn et al, ${ }^{21}$ Pereira et $\mathrm{al}^{15}$ and Nertila et $\mathrm{al}^{12}$ where age $>60$ years, as in another study, $>50$ years, were predictors of risks. ${ }^{22,23,24}$ Unlike ours, large population and age $>50$ years in these studies ${ }^{12,15,21}$ perhaps, might explain the observed disparity.

This study found no significant association between obesity and PPCs, which agrees with that in 2 studies in Brazil and Asia ${ }^{15,20}$ but disagrees with that in another report in USA. ${ }^{21}$ Obesity causes reduced lung volumes, ventilation/perfusion mismatch and relative hypoxemia ${ }^{24,25}$ which may worsen with anesthesia and so may increase the risk of pulmonary complications. However, these were not observed in this study. Perhaps, the dominantly normal body mass index (BMI) noted in this study might explain the dissociation between obesity and PPCs.

This study observed a significant association between pre-operative presence of cough, shortness of breath and PPCs. It further showed that pre-operative cough predicted PPCs, similar to the report by Pereira et al. ${ }^{1}$ The presence of these symptoms suggests pre-existing respiratory system disease which makes the lung more susceptible to the deleterious effect of changes in lung volume and mechanics during surgeries. Pre-existing respiratory disease, mirrored by these symptoms, influenced the development of PPCs, as found in the study.

In this study, though $50 \%$ of the current smokers developed PPCs, the association was not significant, similar to the report by Kanat et al. ${ }^{20}$ However, it disagrees with the observations by Barrera et al, ${ }^{26}$ Mitchell et $\mathrm{al}^{10}$ and Dilworth et al, ${ }^{27}$ The small population size and few numbers of current smokers could explain the outcome in this study, similar to that by Kanat et $\mathrm{al}^{20}$ but differing from those 3 workers ${ }^{10,26,27}$ who have more smokers with longer pack years of smoking.

Expectedly, ASA class I and II have no significant association with PPCs, as these levels usually have low risk of developing surgical complications, as found in this study. This agrees with the report by Kanat.et $\mathrm{al}^{20}$ but differs from that by Smetana et $\mathrm{al}^{24}$ which documented that patients in ASA > II have 4.87 fold increased risk of developing PPCs. Nonetheless, they have more patients in ASA III and IV classes than were observed in this study. Many $(62 \%)$ of the participants have abnormal lung function; they were mainly restrictive, some mild, few moderate and yet others severe. This pattern could be explained by the dominant abdominal pains and swelling. Classing restriction into normal, mild, moderate and severe may depend on the site, size of abdominal lesion and degree of pain. Those who have normal spirometry were mainly participants with small lesions without pain, lower abdominal and pelvic conditions. There was no obstructive pattern found in this study. Perhaps this was attributable to the small number of the patients who were smokers.

In this study, low percentage predicted FEV1 and low predicted FVC were significantly associated with PPCs, agreeing with the reports in 3 studies ${ }^{15,20,28}$ despite the high number of participants with obstructive spirometry pattern they observed.

Albumin aids opsonization and granulocyte function. Low serum albumin is a poor prognostic feature in pneumonia. ${ }^{29}$ Most of this study participants have normal serum urea and albumin which might account for the absence of an association between them and PPCs in this study. This finding is similar to that documented by Kanat et $\mathrm{al}^{20}$ but contrary to that observed by Varut et al. ${ }^{30}$ It was further noted that the latter involved only colon cancer patients who were chronically ill and at risk of malnutrition and malabsorption.

Increasing age creates vulnerability for respiratory and cardiac diseases with evident chest radiograph abnormalities. ${ }^{31}$ In this study consolidation was significantly associated with PPCs. The complications comprised of new infiltrates and worsening radiographic findings post-operatively, supporting the assertion that an already diseased lung is at higher risk of worsening pre-existing condition. This contrasts with the observations reported by Kanat et al. ${ }^{20}$

General anesthesia alters lung volumes, impairs respiratory muscles and mucociliary actions. However, this study found no significant association between general anes- 
thesia and PPCs, similar to those by Pedersen et $\mathrm{al}^{32}$ and Kanat et $\mathrm{al}^{20}$ but differing from those by Grigorakos et $\mathrm{al}^{33}$ and Rodgers et $\mathrm{al}^{34}$

Additional use of long-acting skeletal muscle relaxants during general anesthesia increases the risks of developing PPCs by prolonged residual neuromuscular blockade which plays a vital role in critical respiratory events in the immediate post-operative period. ${ }^{35}$ This study however, did not observe any significant association between the type of muscle relaxants and PPCs. However, significant association between duration of surgery/anesthesia and PPCs was observed in this study, contrary to the studies by Nertila et $\mathrm{al}^{12}$ and Kiekkas .et al. ${ }^{36}$ The shorter duration of surgery and anesthesia for most participants in this study might have minimized the residual effect of these muscle relaxants. Many of the surgeries in this study lasted $<2$ hours as these effects are more evident in prolonged surgeries. This is similar to the findings of Kanat et $\mathrm{al}^{20}$ but contrary to those of McAlister et al, ${ }^{37}$ Celli et $\mathrm{al}^{38}$ and Pederson et $a{ }^{39}$ where many patients have surgeries $>3$ hours.

The closer the incision to the chest and diaphragm, the greater the risks of developing PPCs. These might result from disruption of respiratory muscle movement. Pain also limits the movement of the chest and splints the diaphragm. ${ }^{13}$ Although $60.6 \%$ of the patients in this study who have upper midline incision developed PPCs, there was no significant association between the type of surgical incision and these complication, contrasting with the findings of Brooks-Brunn et $\mathrm{al}^{21}$ which have a large study size; and many of their subjects have co-morbidities. Absence of other procedure- and patient-related risk factors in this study might be explained by this difference.

This study found no significant association between the presence of endotracheal tube with assisted ventilation during general anesthesia and PPCs, contrary to the findings of Joia.et al, ${ }^{40}$ a study in which both elective and emergency abdominal surgeries were involved.

The prevalence of $52 \%$ of early PPCs in this study is similar to $58.3 \%$ observed by Kanat et $\mathrm{al}^{20}$ that enrolled 60 participants, but is higher than $14 \%$ reported by Pereira et $\mathrm{al}^{15}$ that studied $>400$ patients, and $11.7 \%$ by Joia et al [40] (with 5075 participants). In the studies by Pereira et $\mathrm{al}^{15}$ and Joia et $\mathrm{al}^{40}$, the participants were also undergoing measures to prevent PPCs like pre-operative incentive spirometry, chest physiotherapy as recommended by their
Ethics Committees. These measures might have reduced the prevalence of the complications in their respective studies. Theirs, like this study, also supports the assertion that early pre-operative intervention could reduce the incidence of PPCs.

Productive cough with basal crepitations was the commonest PPC found in this study. Among these, $8 \%$ have new infiltrates and pneumonic consolidation on their post-operative chest X-ray. In contrast, pneumonia was the commonest PPC reported by Kanat. et $\mathrm{al}^{20}$ and Joia et $a{ }^{40}$ The study by Pereira et $\mathrm{al}^{15}$ documented broncho-constriction, a study that has dominantly chronic obstructive pulmonary disease (COPD) patients with significant smoking history, intubation and surgeries $>210$ minutes, unlike those in this study with one COPD patient, and surgery $<2$ hours.

This study found that only one patient has suspicious ARDS and this patient needed assisted ventilation but died in the course of this study.

The post-operative respiratory rate and pulse rate were significantly higher in those who developed PPCs than in those without complications, suggesting the presence of complications, perhaps, infection in these subjects.

Overall, this study has demonstrated that pre-operative pulmonary symptoms and features were associated with PPCs in subjects undergoing abdominal surgeries in NAUTH, Nnewi, Nigeria. There is a need for clinicians, surgeons, anesthesiologist and other stakeholders involved in patients' management to institute adequate pre-operative pulmonary assessment, including mandatory spirometry, of these patients prior to abdominal surgeries with a view to whittling down adverse post-operative pulmonary complications.

\section{Conclusion}

The prevalence of post-operative pulmonary complications was high in this study. Pre-operative cough, shortness of breath, consolidation, low percentage predicted FEV1 and FVC were associated with PPCs. There is a need for stakeholders to institute adequate pre-operative pulmonary assessment, including mandatory spirometry, prior to abdominal surgeries, with a view to whittling down adverse post-operative pulmonary complications.

\section{Limitations of the study}

Arterial blood gases for the participants were not done. These if done would have improved the overall results of 
the oximeter especially in those who have anemia. And peripheral vasoconstriction. Surgeries were performed by different categories of surgeons with varying years of experiences which might possibly affect outcomes. The study population size was small. A larger study sample, or overtly a multi-center study, would have been more representative of the population.

\section{Conflict of interest}

The authors declare that there is no conflict of interest.

\section{References}

1. Katherine Habeeb: Pre-operative assessment of pulmonary patient. In Parsons PE, Heffner JE(eds): Pulmonary / Respiratory Therapy Secrets, $3^{\text {rd }}$ ed. Philadelphia. Mosby Elsevier. 2009, p 38.

2. Koegelenberg CFN, Diacon A.N, Bolliger CT. Preoperative pulmonary evaluation in principles of respiratory care, Clinical Respiratory Medicine, $3^{\text {rd }}$ ed. Mosby Elsevier's. 2008, p 275.

3. Rudra A, Sudipta D. Post-operative pulmonary complication. Indian J. Anaesth.2006; 50(2):89-98.

4. Warner DO. Preventing postoperative pulmonary complications: the role of Anaesthesiologist. Anaesthesiology. 2000; 92:1467-1472 PubMed.

5. Smetana GW. Pre-operative pulmonary evaluation. $N$ Engl J Med. 1999; 340:937 944 PubMed.

6. Dimick JB, Chen SL, Taheri PA, Henderson W. Hospital costs associated surgical complications; A report from the private sector-National Surgical Quality Improvement Program. J Am Coll Surg. 2004; 199(4): 531 PubMed.

7. Finlay A, McAlister FA, Kimberly B, Jeremy M, John B, Michael J. Incidence of and Risk factors for pulmonary complications after non-thoracic surgery. Am J Respir Crit Care Med. 2005; 171:514-517.

8. Dureuil B, Cantineau JP, Vogel J, Desmont JM. Vital capacity and diaphragmatic function after abdominal surgery. Anaesthesiology. 1984; 61: A478.

9. Torrington KG, Henderson CJ. Pre-operative respiratory therapy. A program of pre-operative risk assessment and individualized post-operative care. Chest. 1988; 93:946-951 PubMed.

10. Mitchell C, Garrahy P, Peake P. Post-operative respiratory morbidity. Identification and risk factors. Aust $N Z$ Surg. 1982; 52(2): 203-209. PubMed.

11. Overview of the management of post-operative pul- monary complications. Available at https://www.uptodate.com/contents/overview.../accessed 11.49am; Dec 31, 2015.

12. Nertila K, Vjollca S, Ilir O. Risk factors for post-operative pulmonary complications after abdominal surgery. Maced J Med Sci. 2016;4(2):259-263.

13. Craig DB. Post-operative recovery of pulmonary function. Anaesth Analg. 1981; 60:46

14. Sugimach K, Ueo H, Natsuda Y, Kai H, Inokuchi K, Zaitsu A. Cough dynamics in oesophageal cancer; prevention of post-operative pulmonary Complications. $\mathrm{BrJ}$ Surg. 1982; 69(12): 734

15. Pereira ED, Fernandes AL, daSilva Ançao M, de Arauja Pereres C, Atallah AN,Faresin SM. Prospective assessment of the risk of post-operative pulmonary complications in patients submitted to upper abdominal surgery. Sao Paulo Med J. 1999 Jul 1: 117(4):151-160.

16. Naunheim KS, Wood DE, Krasna MJ. Predictors of operative mortality and cardiopulmonary morbidity in the National Emphysema Treatment Trial. J Thorac Cardiovasc Surg. 2006; 131:43-

17. Fisher BW, Majumdar SR, McAlister FA. Predicting pulmonary complications after non thoracic surgery; A systemic review of blinded studies. Am J Med. 2002; 112: 219-225 PubMed.

18. Chapman S, Robinson G, Stradling J, West S, Appendix 5: lung function testing. Oxford handbook of respiratory medicine 2nd edition New York. Oxford university press; 2008: 827-836.

19. Femi-pearse D. Ventilatory functions including anthropometric correlations in Nigerians. University of Aberdeen 1967(MD thesis)

20. Kanat F, Golcuk A, Teke, T, Golcuk M. Risk factors for post-operative pulmonary complications in upper abdominal surgery. ANZ J. Surg. 2007. Mar. 77(33): 135-141 21. Brooks-Brunn JA. Predictors of post-operative pulmonary complications following abdominal surgery. Chest, 1997; 111 (3): 564 PubMed.

22. Canet J, Gallart L, Gomar C et al. Predictors of postoperative pulmonary complications in a population based cohort. Anesthesiology. 2010; 113: 1138-50.

23. Mazo V, Sabate S, Canet J et al. Prospective external validation of a predictive score for postoperative pulmonary complications. Anesthesiology. 2014; 121: 219-31.

24. Smetana GW, Lawrence VA, Cornell JE. American college of physicians. Pre-operative pulmonary risk strat- 
ification for non-Cardio thoracic surgery. Systematic review for the American college of physicians. Ann Intern Med. 2006; 144 (8): 581.

25. Kroenke K, Lawrence VA, Theroux JF, Tuley MR, Hilsenbeck S. Post-operative complications after thoracic and major abdominal surgery in patients with and without obstructive lung disease. Chest. 1993; 104 (5): 1445-1451. 26. Barrera R, Shi W, Amar D. Smoking and timing of cessation: impact on pulmonary complications after thoracotomy. Chest, 2005; 127: 1977-1983 PubMed.

27. Dilworth JP, White RJ. Post-operative chest infections after upper abdominal surgery: an important problem for smokers. Respir Med. 1992; 86: 205-210 PubMed. 28. Fuso L, Cisternino L, Di Napoli AD,Di Cosmo V,Tramaglino LM,Basso S,Spadaro S,Pistelli R. Role of spirometric and arterial gas data in predicting pulmonary complications after abdominal surgery. Respire. Med. 2000; 94:1171-1176 PubMed.

29. Arozullah AM, Daley J, Henderson WG, Khuri SF. Multifactorial risk index for predicting post-operative respiratory failure in men after major non cardiac surgery. The national veterans' administration surgical quality improvement program. Ann Surg. 2000; 232(2): 242-253. PubMed.

30. Varut L, Vitoon C, Supatre L, Thawatchai A, Wiroon Boonnuch, Asada Methasade, Darin Lohsiriwat Hypoalbuminaemia is a predictor of delayed post-operative bowel function and poor surgical outcomes in colon cancer patients. Asia Pac J Chin Nutr. 2007; 16(2): 213 - 217.

31. Tisi GM. Pre-operative evaluation of pulmonary function: validity, indications and benefits. Am Rev Respir Dis.1979; 119:293-310 PubMed.

32. Pedersen T, Viby-Mogensen J, Ringsted C. Anaesthetics practice and post-operative pulmonary complications. Acta Anasesthesiol Scand. 1992 Nov.; 36(8): 812-818.

33. Grigorakos L, Sotiriou E, Koulendi D, Michail A, Alevizou S, Evagelopoulou P. Preoperative pulmonary evaluation as a prognostic factor in patients undergo- ing upper abdominal surgery. Hepatogastroenterology. 2008; 55(85):1229-1232.

34. Rodgers A, Walker N, Schug S, McKee A, Kehlet H, van Zundert A, Sage D, Futter M, Saville G, Clark T, MacMahon S. Reduction of post-operative mortality and morbidity with epidural or spinal anaesthesia: results from our view of randomized trials. BMJ. 2000; 321: 1493.

35. Berg H, Roed J, Viby-mogensen J, Mortensen CR, Engbaek J, Skovgaard LT, Krintel JJ. Residual neuromuscular block is a risk factor for post-operative pulmonary complications. A prospective, randomized and blinded study of post-operative pulmonary complications after atracurium, vecuronium and pancuronium. Acta Anaesthesiol Scand. 1997; 41:1095.

36. Keikkas P, Bakalis N, Konstantinoli E, Aretha D, Residual Neuromuscular blockade and post-operative critical respiratory even: Literature review. J clin Nurs. 2014 Nov; 23(21-22): 3025-3035.

37. Mcalister FA, Khan NA, Straus SE, Papaioakim M, Fisher BW, Majumdar SR, Gajic O, Daniel M, Tomlinson G. Accuracy of pre-operative assessment in predicting pulmonary risk after non thoracic surgery. Am J. Respir Criti Care Med. 2003; 167(5): 741-744.

38. Celli BR, Rodriguez KS, Snider GL. A controlled trial of intermittent positive pressure breathing, incentive spirometry and deep breathing exercises in preventing pulmonary complications after abdominal surgery. Am Rev Respir Dis. 1984 July; 130(1): 12-15.

39. Pederson T, Eliasen k, Henriksen E. A prospective study of risk factors and cardiopulmonary complications associated with anaesthesia and surgery: risk indicators of cardiopulmonary morbidity. Acta Anaesthesiol Scand. 1990; $34: 144$.

40. Joia Neto L, Thomas J.C, Cardoso J.R. Post-operative respiratory complications from elective and urgent/ emergency surgery performed at a university hospital. J. Bras. Pneumol. 2005; 31(1):41-47. 